\title{
An Exploratory Factor Analysis and Reliability Analysis of the Perceived Severity and Response to Bullies and Victims of Bullying Questionnaire
}

\author{
Tudorita Grădinariu, Gabriela Monica Assante••
}

\begin{abstract}
This study aimed to test the reliability of the Perceived Severity and Response to Bullies and Victims of Bullying Questionnaire (PSRBVBQ) for middle school teachers ( $N=322$ teachers), using exploratory factor analysis and reliability analysis. PSRBVBQ assesses teachers' responses to bullying using situational scenarios. It includes two vignettes for each type of bullying (physical, verbal and relational) to analyze the perceived severity, likelihood of responding to the bully, likelihood of responding to the victim. Exploratory factor analysis indicated a three-factor solution: perceived severity ( $\alpha=.73)$, the likelihood of responding to the bully $(\alpha=.84)$, the likelihood of responding to the victim ( $\alpha=.89$ ). These results indicate a good internal consistency of the items in each scale, especially for the likelihood of responding to the victim and for the likelihood of responding to the bully scales. The results show that the PSRBVBQ has good psychometric properties and can be successfully used in research regarding Romanian teachers' perceptions and their response to bullying. Also, more than one-third of teachers perceive verbal aggression as serious, while much less perceive relational aggression as very serious. At the same time, we found that the perceived severity predicts the probability of the teacher's reaction to the incidents of aggression.
\end{abstract}

Keywords: bullying, perceived severity, teachers response, EFA

\section{Introduction}

For a long time, the literature on the thematic field of bullying focused on its causes, prevention strategies, and the reduction of bullying in schools. Less attention was paid to teachers' perceptions and their responses to bullying (Bush, 2009). At the school level, teachers are the ones who manage events of bullying between students. Hence, they play an important role in the safety of students in schools (Duong \& Bradshaw, 2013). Recently, a growing interest in investigating teachers' perceptions and reactions to the three types of bullying (physical, verbal and relational) can be observed (Olweus, 2003). Teachers' reactions to bullying events can influence the future behavior of the bully,

\footnotetext{
- Assistant Professor, PhD, Educational Sciences Department, Alexandru Ioan Cuza University, Iași, Romania, correspondence author: tudorita.gradinariu@uaic.ro

•-Assistant Professor, PhD, Educational Sciences Department, Alexandru Ioan Cuza University, Iași, Romania, correspondence author: monica.assante@uaic.ro
} 
victim, and bystanders. Moreover, the school can contribute to either maintaining or perpetuating bullying behavior between students through inappropriate teacher reactions to school violence, inadequate student-teacher relationships, lack of teacher support, non-involvement, or poor involvement of students in school activities (Swearer \& Hymel, 2015).

For example, Craig, Henderson and Murphy (2000) found that the low percentage of teachers who intervened was due to their inability to effectively recognize and identify bullying in school, especially verbal bullying and social exclusion, which is more difficult to detect than physical bullying. Also, some hidden forms of bullying, such as social exclusion and rumors, are perceived by teachers as less serious than open, direct, and observable as physical and verbal bullying (Craig, Bell \& Leschied, 2011).

Nowadays, scholars focus on identifying the potential explanatory factors of the lack of intervention and reaction of teachers to bullying. Consequently, some authors claim that the perceived severity has the basic subjectivity in interpreting bullying that can affect teachers' responses (Yoon \& Kerber, 2003). Thus, verbal and relational bullying tend to be perceived as less severe, which decreases the likelihood of teacher intervention (Stankiewicz, 2007).

\section{Bullying in school}

The concept of bullying was first introduced in 1978 by the Norwegian psychologist Dan Olweus, as a result of school surveys on violent behavior among students. Olweus says that a student is bullied "when he is repeatedly and over time exposed to negative actions by one or more students" (Olweus, 1993, p. 9). The negative action manifests "when someone intentionally inflicts or attempts to inflict, injury or discomfort upon another" (Olweus, 1993, p. 9). We can talk about bullying when a student is hit, pushed, teased, threatened, locked in a room, when tickets are sent to him with malicious, obscene, unpleasant content and when other colleagues do not talk to him or he (Smith \& Sharp, 1994).

The term bullying should not be used when two students have the same ratio of physical or mental strength, fight, or quarrel. In order to use the term "bullying", there must be a power imbalance (Olweus, 1994). Bullying is an interaction in which a dominant individual (bully) repeatedly manifests bullying behavior with the intention of causing the suffering of a less dominant individual (victim), (Olweus, 1991). There are two meanings of bullying: broadly, systematic abuse of power, and narrowly, the psychological or physical domination of a weaker person by a stronger person or group (Rigby, 2007).

\section{Physical bullying}

Physical bullying is most easily recognized due to the obvious and direct manifestations of the bully (Veenstra et al., 2005), and is usually attributed to boys (Lee, 2009). It is action-oriented and includes any type of intentional behavior that causes bodily harm: 
hitting, pushing, punching, kicking (Newman et al., 2000). There is a complex picture of the forms of manifestation of physical bullying: hitting, pushing, spitting, destroying or stealing personal property, throwing stones (direct bullying), and inciting a friend to hit another person (indirect bullying), (Olweus, 1993; Rigby, 2007).

\section{Verbal bullying}

Verbal bullying occurs when a student uses a certain kind of language to gain power and control. This type of bullying is quite widespread because it is more likely to occur without attracting the attention of school staff (Newman et al., 2000). Verbal bullying includes behaviors such as sarcasm, teasing, nicknames, verbal insults (direct bullying) and spreading false rumors, and inciting one person to assault another person (indirect bullying), (Olweus, 1993; Rigby, 2007).

\section{Relational bullying}

Relational bullying includes behaviors such as manipulating friendships (threatening, persuading to break a friendship), exclusion from the group and launching false rumors (false stories) about the victim to encourage peer rejection (Lee, 2009). This type of bullying is closely related to emotional aggression and occurs most frequently among girls (Newman et al., 2000).

\section{Perceived severity}

The perceived severity of bullying by teachers predicts their likelihood of intervention (Dedousis-Wallace \& Shute,2009). Thus, the more severe the bullying is perceived, the more likely the teacher is to respond (Harrison, 2015). Teachers perceive relational bullying as less severe, and they are less likely to intervene than in physical and verbal bullying (Yoon\&Kerber, 2003). Some hidden forms of bullying, such as social exclusion and rumors, are perceived by teachers as less severe than overt, direct, and observable bullying such as physical and verbal (Craig, Bell \& Leschied, 2011). The low percentage of teachers who intervened is due to their inability to effectively recognize and identify bullying behavior, especially verbal and social exclusion, which is more difficult to detect than physical bullying (Craig et al., 2000). If teachers are unaware of the consequences or do not perceive the severity of these behaviors, they tend to adopt a passive attitude hence a reduced likelihood of intervention (Yoon \& Kerber, 2003).

The main objective of this study is to explore the reliability of the Perceived Severity and Response to Bullies and Victims of Bullying Questionnaire for teachers. These dimensions were not explored in previous research and, by these means, we will provide a situational judgment test, as an alternative to other existing measures. The PSRBVBQ represents a situational judgment measure that presents realistic scenarios and asks individuals to rank the responses, currently considered one of the best questionnaires for measuring teachers' perception (Harrison, 2015). 


\section{Method}

\section{Participants and procedure}

This study includes 322 middle school teachers, (281 women and 41 men), with ages situated between 20 to 69 years old, from 23 middle schools situated in the city. All the local middle schools were contacted and asked to participate in the study. The research details were communicated to each school director, which disseminated further the information to the school teachers. The directors provided a list of participants that were willing to participate in the study. Consequently, the subjects were contacted, signed informed consent and completed the questionnaire voluntarily and anonymously. The teachers completed the questionnaires at school, in their offices, or their classrooms. The Ethics Committee of the Faculty gave its approval for the present research.

Table 1. Participants teaching experience

\begin{tabular}{ccc}
\hline Teaching experience & $n$ & $\%$ \\
\hline 0-2 years & 14 & 4.34 \\
3-5 years & 21 & 6.52 \\
6-10 years & 42 & 13.04 \\
11-20 years & 117 & 36.33 \\
21-30 years & 70 & 21.73 \\
over 31 years & 58 & 18.01
\end{tabular}

\section{Instrument}

The Perceived Severity and Response to Bullies and Victims of Bullying Questionnaire, built by Bush (2009) and later developed by Harrison (2015), was designed based on previous studies and real-life media reports on bullying (Bush, 2009; Yoon et al., 2014 apud. Harrison, 2015). Two vignettes were eliminated based on the topic, they referred to cyber-bullying and our focus is on classroom bullying. Therefore, the measure includes six bullying scenarios, two for each type of bullying (physical, verbal, and relational). Harrison (2015) specifies that the types of bullying have to be separated in order not to influence participants' responses. The scenarios were designed in an impartial manner with no reference to individual characteristics such as ethnicity, race, and religion, as these factors could have affected the responses. For each situation, the teachers had to rank the perceived severity, the likelihood of responding to the bully, the likelihood of responding to the victim, on a seven-point Likert scale. In order to adapt the questionnaire for the Romanian population, the forward-backward translation method 
was employed. Four expert translators were used during the translation process. Two of them first translated the scenarios into Romanian, next the provided version was translated back into English. Small changes were made, e.g., one of the scenarios was replaced with one that is more common in our schools. Our version reflected the type of bullying in Harrison's version (relational bullying: spreading rumors). Finally, the two versions were confronted and the Romanian version was finalized.

To identify the best instrument to measure teachers' perception over the severity of bullying and their reaction towards the bullies and the victims, we consulted a vast number of recent studies and doctoral theses in the the field of bullying aggression. Thus, we found the PSRBVBQ, currently being one of the best tools to measure the perception of the severity of bullying by teachers, the likelihood of a reaction to the bully and the victim, and the resulting reactions in these situations (Harrison, 2015). At the same time, we have identified another similar instrument that measures the severity of teachers' perceptions of bullying, Teachers' Perception of Classroom Behavior Questionnaire (TPCBQ) (Zerillo, 2010) that uses vignettes to investigate teachers' and students' perceptions of bullying. The option for Harrison's tool (2015) is based on the fact that it presents scenarios for each type of bullying (physical, verbal and relational), teachers being invited to assess the severity and the probability of reaction for each type in the case of the bully and the victim. Zerillo's (2010) questionnaire does not contain separate scenarios for the bully and the victim. However, it includes bullying situations that teachers must evaluate in terms of significance.

\section{Results}

Preliminary analysis showed that high school teachers perceive relational aggression as less serious than physical and verbal aggression. Therefore, 38.6\% $(\mathrm{N}=126)$ of teachers perceive verbal aggression as serious, while $23.8 \%$ of them perceive relational aggression as very serious. At the same time, we found that the perceived severity predicts the probability of the teacher's reaction to the incidents of aggression. Thus, if teachers perceive an aggressive act as serious, there is an increased likelihood that they will intervene in the incidents of aggression. In all three situations of aggression examined (physical, verbal and relational) we obtained strong correlations between the perceived severity and the probability of reaction towards the aggressors and the victims of bullying. For example, there is a positive association between perceived severity and likelihood of reaction to victims of relational aggression ( $r=.557, p=.000<0.005)$. At the level of the scientific literature, it is recognized that teachers' reaction influences the future behaviors of students involved in aggression (Yoon \& Kerber, 2003).

The purpose of this research phase was to investigate the reliability of the items and the internal structure of the constructs measured. Therefore, exploratory factor analysis was conducted to evaluate the structure of the factors. Second, a reliability analysis was performed. The statistical analyses were performed using SPSS 26.0. 
Exploratory factor analysis was conducted on the 18 items with an Oblimin with Kaiser Normalization rotation using the Principal Axis Component Factoring method. In this study, the three factors (the perceived severity, the likelihood of responding to the bully and the likelihood of responding to the victim) were used to determine the pattern of the structure in the 18-item PSRBVBQ and were used to create a scree plot (Thompson, 2004).

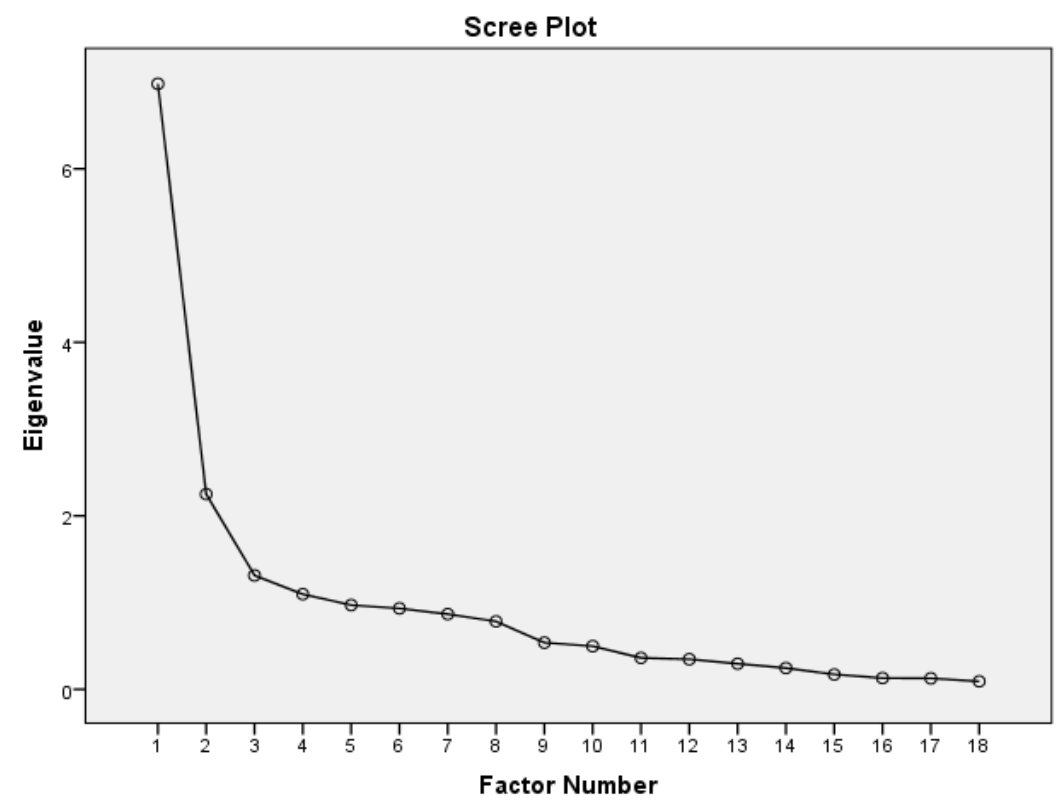

Figure 1. Scree Plot for the questionnaire Perceived Severity and Response to Bullies and Victims of Bullying Questionnaire

The Kaiser-Meyer-Olkin Measure was used to verify the sampling adequacy for the factor analysis, KMO $=0.81>0.60$ which means that EFA can be performed (Kaiser, 1974). Barlett's test of sphericity $\chi^{2}(153)=3762,570, p<0.001$, suggests that itemscorrelations are sufficiently large for EFA and a three-factor solution resulted. The 18item structure explained $51.45 \%$ of the variance in the pattern of relationships among the items. The percentages explained by each factor were $36.35 \%$ (perceived seriousness), $10.21 \%$ (likelihood of response to the bully), respectively $4.88 \%$ (likelihood of response to the victim). The correlation between factor 1 (perceived seriousness) and factor 2 (likelihood of response to the bully) was .462; the correlation between factor 2 and factor 3 (likelihood of response to the victim) was .177; the correlation between factor 1 and factor 3 was .020 (Table 2). 
Table 2. Factor Correlation Matrix

\begin{tabular}{cccc}
\hline Factor & 1 & 2 & 3 \\
\hline 1 & 1.000 & .462 & .020 \\
\hline 2 & .462 & 1.000 & .177 \\
\hline 3 & .020 & .177 & 1.00
\end{tabular}

Extraction Method: Principal Axis Factoring

Rotation Method: Promax with Kaiser Normalization

The factorial analysis of the 18 items that measure teachers' perceptions and likelihood of reaction towards bullies and victims validated a three factorial structure and partially satisfies the statistical criteria related to this type of analysis. The factors are balanced, six items per factor, each item loading in a single factor. Hence, the instrument that measures perceived severity and likelihood of responding to bully and victim of bullying contains three scales: the scale that measures the perceived severity contains 6 items (items 13,14,10,1,16,7); the scale that measures the likelihood of responding to bully contains 6 items (items $6,12,15,18,9,3$ ); the scale that measures the likelihood of responding to the victim contains 6 items (items 5, 8, 17, 2, 11, 4).

Table 3. Eigenvalues, Total Variances Explained for the Three-Factor Structure

\begin{tabular}{|c|c|c|c|c|c|c|c|}
\hline Factor & $\begin{array}{c}\text { Initial } \\
\text { Eigenvalue }\end{array}$ & & & & $\begin{array}{c}\text { Extraction } \\
\text { Sums of } \\
\text { Squared } \\
\text { Loadings }\end{array}$ & & \\
\hline & Total & $\begin{array}{c}\% \text { of } \\
\text { Variance }\end{array}$ & $\begin{array}{c}\text { Cumulative } \\
\%\end{array}$ & Total & $\begin{array}{c}\% \text { of } \\
\text { Variance }\end{array}$ & $\begin{array}{c}\text { Cumulative } \\
\%\end{array}$ & Total \\
\hline 1 & 6,980 & 38,778 & 38,778 & 6,544 & 36,356 & 36,356 & 4,082 \\
\hline 2 & 2,250 & 12,498 & 51,276 & 1,839 & 10,216 & 46,572 & 4,917 \\
\hline 3 & 1,314 & 7,298 & 58,574 & 879 & 4,883 & 51,455 & 4,545 \\
\hline
\end{tabular}

Extraction Method: Principal Axis Factoring 
Table 4. Items and factor loadings of the three-factor model using a principal axis factoring

\section{Items}

13. perceived severity- relational

4. perceived severity - physical

10. perceived severity - verbal

1. perceived severity - physical

16. perceived severity - relational

7. perceived severity - verbal

6. likelihood of responding to the victim - physical

12. likelihood of responding to the victim - verbal

15. likelihood of responding to the victim - relational

18. likelihood of responding to the victim - relational

9. likelihood of responding to the victim - verbal

3. likelihood of responding to the victim - physical

5. likelihood of responding to the bully - physical

8. likelihood of responding to the bully - verbal

17. likelihood of responding to the bully - relational

2. likelihood of responding to the bully - physical

11. likelihood of responding to the bully - verbal

14. likelihood of responding to the bully - verbal

Eingenvalue

Variance explained

\begin{tabular}{l|l|l|l}
\multicolumn{3}{c|}{ Factor loadings } & Communalities \\
\hline $\begin{array}{l}\text { F1 } \\
, 790\end{array}$ & $F 2$ & $F 3$ &, 582 \\
, 673 & & &, 563 \\
, 482 & & &, 380 \\
, 454 & & &, 240 \\
, 417 & & &, 344 \\
, 328 & & &, 322 \\
&,- 858 & &, 815 \\
&,- 845 & &, 700 \\
&,- 825 & &, 790 \\
&,- 674 & &, 622 \\
&,- 670 & &, 707 \\
&,- 642 & &, 408 \\
& &,- 776 &, 569 \\
& &,- 639 &, 569 \\
& &,- 545 &, 568 \\
& &,- 544 &, 485 \\
& &,- 379 &, 462 \\
6,544 & 1,839 &,- 325 &, 136 \\
& &, 879 & \\
& 10,216 & 4,883 & \\
& & &
\end{tabular}

Item Analysis for Reliability

To test the reliability of each factor of the questionnaire, an item analysis was conducted. The satisfactory internal consistency index varies from 0.70 to 0.90 (Blunch, 2008) and all three factors on this scale had a high rating for reliability. The Cronbach's alpha for perceived severity, the likelihood of responding to the bully, and the likelihood of responding to the victim were $.732, .841$, and .897 .

Table 4. Cronbach's Alpha for Each Factor of the PSRBVBQ

Number of Alpha

items Cronbach value

\begin{tabular}{ccc}
\hline Perceived seriousness & 6 & .732 \\
\hline Likelihood of response to the bully & 6 & .841 \\
\hline Likelihood of response to the victim & 6 & .897 \\
\hline
\end{tabular}




\section{Discussions}

The present study focuses on the examination of the psychometric properties of the Romanian version of the Perceived Severity and Response to Bullies and Victims of Bullying Questionnaire, namely, internal consistency and factors structure. One limitation of this study is the socio-cultural influences that have an impact on teachers' perceptions of bullying. The magnitude of the bullying phenomenon in schools reflects the general state of violence in the community (Adăscăliță et al, 2017). Social, cultural norms, myths can influence teachers' perceptions of how they experienced violence when they were students. In this sense, we discuss the educational practices in Romania from thirty years ago in terms of disciplining the children when physical violence predominated. Convictions and beliefs that assert some positive effects of physical punishment may influence how teachers perceive the severity of physical violence. According to Byers et al. (2011) argue that traditional forms of violence, namely physical violence, are better known and understood, which is why they are no longer perceived as very serious. Moreover, the predominant age segment of our study is represented by the 40-49 years age category which means that a significant number of teachers were students thirty years ago. Specifically, there is a possibility that teachers may have witnessed violence in schools or other settings during childhood, which explains the desensitization and corrosion of their ability to distinguish between serious and very serious forms of aggression. This observation is in agreement with the results of the qualitative study conducted by Mishna et al. (2006) which brings to light an important aspect, most of the teachers investigated in their study stated that they were victims of bullying when they were students. At the same time, experienced teachers become desensitized to hostility to compensate for the lack of intervention skills in offensive incidents (Bauman \& Del Rio, 2006).

At the beginning of this paper, we mentioned that the authors of two independent studies contributed to the construction of this questionnaire. The version we use is the latest published and contains some changes. The first objective was to adapt the questionnaire to the Romanian population. The analysis of the exploratory factors shows that the factorial structure with 3 factors, compared to factor 2 and factor 4 , is the most stable, because the factors are balanced ( 6 items per factor) and each item loads a single factor. This is the main advantage of the model. The data obtained highlight the threefactor factorial structure similar to the initial study (Harrison, 2015). Although the author of the questionnaire built the instrument around these three factors, he failed to provide data on reliability or validity indicators. Therefore, it is impossible to contrast our results. Being a scenario based questionnaire validity testing requires more specific analysis such as Generalizability Theory or Item-response theory which are not covered by the present research.

Some teachers might have difficulties in identifying different types of bullying and their psychological and academic consequences (Yoon \& Kerber, 2003). Therefore, we considered this instrument as the most suitable for Romanian teachers. This 
questionnaire exposes them to concrete scenarios from school reality. Therefore, it should amplify teachers' objective output over the situation. The questionnaire estimates the severity of hostility scenarios for both the bully and the victim for each type of bullying (physical, verbal, and relational). This questionnaire can be used to explore teachers' perceptions of bullying.

\section{Conclusion}

We consider this instrument as an useful tool in Romanian school practice for identifying teachers' perceptions regarding the three types of aggression: physical, verbal and relational. The data collected could also indicate teachers' training needs regarding bullying prevention. Teachers and school counselors can access the Romanian version of the questionnaire in the author's paper (Gradinariu, 2021).

\section{References}

Adascăliță, V., Josanu, R., Moldovanu, I., Epoian, T., Prevenirea violenței în instituția de învățământ. Ghid metodologic. Chișinău, 2017.

Arseneault, L., Bowes, L., \& Shakoor, S. (2010). Bullying victimization in youths and mental health problems: Much ado about nothing? Psychological Medicine, 40(5), 717-729. DOI:10.1017/0033291709991383.

Bauman, S., \& Del Rio, A. (2006). Preservice Teachers' Responses to Bullying Scenarios: Comparing Physical, Verbal, and Relational Bullying. Journal of Educational Psychology, 98(1), 219-231. doi:10.1037/0022-0663.98.1.219.

Blunch, N. J. (2008). Introduction to structural equation modelling using SPSS and AMOS. Thousand Oaks, CA: Sage Publications Ltd.

Bush,M.D., (2009). A quantitative investigation of teachers' responses to bullying (Doctoral dissertation). Retrieved from https://dspace.iup.edu/bitstream/handle/2069/179/Michael\%20Bush.pdf?

Craig, W.M., Henderson, K., \& Murphy, J. (2000). Prospective teachers' attitudes toward bullying and victimization. School Psychology International, 21, 5-21.

Craig, K., Bell, D. \& Leschied, A. (2011). Pre-service Teachers' Knowledge and Attitudes Regarding SchoolBased Bullying. Canadian Journal of Education, 34 (2), 21-33.

Dedousis-Wallace, A., Shute, R. H. (2009). Indirect bullying: Predictors of teacher intervention, and outcome of a pilot educational presentation about impact on adolescent mental health. Australian Journal of Educational \& Developmental Psychology. 9, 2-17.

Duong, J. \& Bradshaw, C.P. (2013). Using the Extended Parallel Process Model to Examine Teachers Likelihood of Intervening in Bullying. Journal of School Health, 83, 422-429.

Gradinariu, T. (2021). Prevenirea agresivității de tip bullying. Repere psihopedagogice pentru o prevenire eficientă. [Bullying prevention. A psycho-pedagogical guidelines for effective prevention], Iași: Editura Universității „Alexandru Ioan Cuza” Iași].

Harrison, K. M., (2015). Bullying in Schools: The Relationship between Educational Staff Burnout and Staff Response to Bullying. LSU Doctoral Dissertations. 2789. Retrieved from https://digitalcommons.lsu.edu/gradschool dissertations/2789.

Kaiser, H.F. (1974) An index of factorial simplicity. Psychometrika, 39, 31-36.

Lee, E. (2009). The relationship of aggression and bullying to social preference: Differences in gender and typesof aggression. International Journal of Behavioral Development, 33(4), 323-33. DOI:10.1177/0165025408098028. 
Mishna, G., Pepler, D., Wiener, J. (2006). Factors Associated With Perceptions and Responses to Bullying Situations by Children, Parents, Teachers and Principals. Victims and Offenders, 1:255-288, DOI: 10.1080/15564880600626163.

Newman-Carlson, D., Horne, A. M., \& Bartolomucci, C. L. (2000). Bully busters: A teacher's manual for helping bullies, victims, and bystanders. Champaign, Ill: Research Press.

Olweus, D. (1991). Bully/victim problems among school children: Basic facts and effects of a school-based intervention program. In I. Rubin \& D. Pepler (Eds.), The development and treatment of childhood aggression (pp. 411-447). Hillsdale, NJ: Erlbaum.

Olweus, D. (1993). Bullying at School: what we know and what we can do. Oxford, Blackwell.

Olweus, D. (1994). Annotation: Bullying at school: Basic facts and effects of a school-based intervention program. The Journal of Child Psychology and Psychiatry, 35(7), 1171-1190.

Olweus, D. (1997). Bully/victims problems in school. Facts and intervention. European Journal of Psychology of Education, 12 (4), 495-510.

Olweus, D. (1999). Sweden. In Smith, P.K., Morita, Y., Junger-Tas, J., Olweus, D., Catalano, R., \& Slee, P. (1999). (Eds). The Nature of School Bullying: A Cross-National Perspective. London \& New York: Routledge, pp. 7-27.

Olweus, D. (2003). A profile of bullying at school. Educational Leadership, 60(6), 12-17.

Rigby, K. (2007). Bullying in schools: and what to do about it. ACER Press.

Smith, P. K., Sharp, S. (1994). School Bullying: insights and perspectives. London: Routledge.

Stankiewicz, K. (2007). School professional trainees' perceptions of bullying (Doctoral dissertation). Available through ProQuest Dissertations and Theses database.

Swearer, S. M., \& Hymel, S. (2015). Understanding the psychology of bullying: Moving toward a socialecological diathesis-stress model. American Psychologist, 70(4), 344-353. doi:10.1037/a0038929.

Thompson, B. (2004). Exploratory and confirmatory factor analysis: understanding concepts and applications. American Psychological Association, Washington DC.

Veenstra, R., Lindenberg, S., Winter, A., Oldehinkel, A., Verhulst, F., \& and Ormel, J. (2005). Bullying and victimization in elementary schools: A comparison of bullies, victims, bully/victims, and uninvolved preadolescents. Developmental Psychology, 41(4), 672-682.

Yoon, J.S. \& Kerber, K. (2003). Bullying elementary teachers' attitudes and intervention strategies. Research in Education, 69, 27-35.

Yoon, J. S. (2004). Predicting teacher interventions in bullying situations. Education and Treatment of Children, 27, 37-45.

Yoon, J. \& Bauman, S. (2014). Teachers: A critical but overlooked component of bullying prevention and intervention. Theory Into Practice, 53(4), 308-314. doi:10.1080/00405841.2014.947226.

Zerillo, C. (2010). Teachers and Bullying Developing a Deeper Understanding of Teachers' Perceptions of Teacher-to-Student Bullying. Hofstra University. 